\author{
The citation for the published journal paper is: Dimaro, L. V., Dawson, D. L., Roberts, N. A., \\ Brown, I., Moghaddam, N. G., \& Reuber, M. (2014). Anxiety and avoidance in psychogenic \\ nonepileptic seizures: the role of implicit and explicit anxiety. Epilepsy \& Behavior, 33, \\ 77-86.
}

\title{
Anxiety and avoidance in psychogenic nonepileptic seizures: The role of implicit and explicit anxiety
}

\author{
Lian V. Dimaro ${ }^{\text {a,* }}$, David L. Dawson ${ }^{\text {b }}$, Nicole A. Roberts ${ }^{\text {c }}$, Ian Brown ${ }^{\text {d }}$, Nima G. Moghaddam ${ }^{\text {b }}$, Markus Reuber ${ }^{\text {e }}$ \\ ${ }^{a}$ Nottinghamshire Healthcare NHS Trust, Rampton Hospital, Retford, Nottinghamshire DN22 0PD, UK \\ b Trent Doctorate in Clinical Psychology, Health, Life and Social Sciences, University of Lincoln, Brayford Pool, Lincoln, Lincolnshire LN6 7TS, UK \\ ${ }^{\mathrm{c}}$ School of Social and Behavioural Sciences, Arizona State University, $4701 \mathrm{~W}$, Thunderbird Road, MC 3051, Glendale, AZ 85306, USA \\ ${ }^{\mathrm{d}}$ Clinical Psychology Unit, Department of Psychology, University of Sheffield, Western Bank, Sheffield S10 2TN, UK

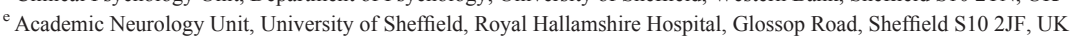 \\ *Corresponding author. lian.dimaro@gmail.com
}

\begin{abstract}
This study examined implicit and explicit anxiety in individuals with epilepsy and psychogenic nonepileptic seizures (PNESs) and explored whether these constructs were related to experiential avoidance and seizure frequency. Based on recent psychological models of PNESs, it was hypothesized that nonepileptic seizures would be associated with implicit and explicit anxiety and experiential avoidance. Explicit anxiety was measured by the State-Trait Anxiety Inventory; implicit anxiety was measured by an Implicit Relational Assessment Procedure; and experiential avoidance was measured with the Multidimensional Experiential Avoidance Questionnaire. Although both groups with epilepsy and PNESs scored similarly on implicit measures of anxiety, significant implicit-explicit anxiety discrepancies were only identified in patients with PNESs ( $\mathrm{p} b .001)$. In the group with PNESs (but not in the group with epilepsy), explicit anxiety correlated with experiential avoidance $(\mathrm{r}=.63, \mathrm{p} \mathrm{b} .01)$ and frequency of seizures $(\mathrm{r}=.67, \mathrm{p} \mathrm{b} .01)$; implicit anxiety correlated with frequency of seizures only $(\mathrm{r}=.56, \mathrm{p} \mathrm{b} .01)$. Our findings demonstrate the role of implicit anxiety in PNESs and provide addi-tional support for the contribution of explicit anxiety and experiential avoidance to this disorder.
\end{abstract}

Keywords: Implicit; Anxiety; Avoidance; Implicit Relational Assessment Procedure; Nonepileptic Seizures

\section{Introduction}

\subsection{Anxiety and avoidance in psychogenic nonepileptic seizures}

Psychogenic nonepileptic seizures (PNESs) bear a superficial resem-blance to epileptic seizures. However, whereas the experiences and behaviors associated with epileptic seizures are caused by abnormal electrical activity in the brain, most PNESs are considered to be a psy-chological dissociative reaction to threatening situations, sensations, emotions, thoughts, or memories [1,2]. Indeed, while psychodynamic, cognitive, behavioral, and systemic psychological theories offer dif-ferent accounts of PNESs [3], all recognize the patient's response to anxiety as a significant contributing factor and suggest that PNESs may reflect an inability, failure, or unwillingness to actively engage with anxiety. This recognition is supported by evidence that patients with PNESs generally report a greater preference for avoidant coping strategies and are more likely to somaticize their distress compared with those with epilepsy [4-10]. Nevertheless, relatively little research has specifically addressed avoidance in PNESs despite its key role in many psychological theories about the etiology of PNESs.

Within the broader psychological literature, avoidance of anxiety or avoidance of other introspective experiences, termed 'experiential avoidance', is frequently associated with psychopathology [11-13]. Experiential avoidance is not merely the avoidance of certain situations but rather the avoidance of one's own thoughts, sensations, and emo-tions, particularly anxiety-provoking ones [14]. Such avoidance can be voluntary or involuntary, with the involuntary aspect arguably most likely to precipitate clinical syndromes such as PNESs [15].

Anxiety itself is a complex physiological and behavioral experience with both 'explicit' and 'implicit' cognitive components [16,17].As detailed below, 'explicit cognition' refers to thoughts or experiences in one's subjective awareness, as typically captured via self-report measures; 'implicit cognition' refers to attitudes, beliefs, preferences, learning processes, emotional experiences, or other knowledge or cognitive processes (e.g., attitudes about oneself or others) that occur outside of conscious awareness and that are captured using indirect measures [18,19]. Implicit and explicit measures are typically unrelated or only modestly related [20]. Discrepancies between the two would ar-guably be more pronounced among patients with limited self-awareness and have, for instance, been demonstrated in patients with borderline personality disorder [21]. Given the types of personality pathology associated with PNESs, including abnormalities of the borderline type [22-24], it may be reasonable to expect similar discrepancies between implicit and explicit measures in patients with nonepileptic seizures. 
Studies comparing anxiety in individuals with PNESs and epilepsy have failed to identify clear and consistent differences, although the prevalence rates of anxiety disorders have been found to be approxi-mately twice as high in both groups as in the general population $[25,26]$. Some studies showed similar mean levels of self-reported anxiety in patients with epilepsy or PNESs [27,28], whereas others found significant [29] or trend-level differences [30]. Such inconsis-tencies may be explained, in part, by the use of explicit measures, which not only are susceptible to social desirability biases but also as-sume a level of insight and awareness and an ability to accurately report on internal states — skills that may be diminished in individuals with neurological disorders or individuals who tend to avoid interoceptive experiences. Self-report measures such as the MMPI, which attempt to circumvent these problems, have been more likely to find group differences [29,31], although findings have not been consistently repli-cated and have been questioned in terms of sensitivity and specificity for the differential diagnosis of epilepsy and PNESs [32] (also discussed in [33]). What is more, while the MMPI has been used extensively, it does not separate clearly between psychopathology and normal findings, does not specifically describe different types of avoidance be-haviors, and cannot measure implicit cognition.

\subsection{Implicit cognition and measurement}

'Implicit cognition' is a term widely used by psychologists to refer to hypothetical psychological attributes (e.g., beliefs about self or others, as noted earlier) that are outside of conscious awareness and, therefore, introspectively inaccessible [34]. Importantly, these cognitions can have a strong impact on physiological responses [35] and behavior [36]. Measures of implicit cognition aim to provide an index of an attitude or cognition without requiring a participant's awareness or conscious access to the attribute under investigation $[37,38]$. This is achieved through tasks where participants respond in an "automatic manner" (p. 347 [39]), with little or no opportunity for attentional con-trollability or self-monitoring [19,40,41].

Implicit measures often employ a response latency (reaction time) paradigm, underpinned by an assumption that implicit cognitive biases can be detected by examining efficiency of cognitive processing $[19,40]$. This can be done through the aggregation of many overt responses (e.g., key presses on computerized tasks), frequently under time pres-sure, and across various types of stimuli (e.g., words or pictures related to a targeted attribute) $[42,43]$. Studies using implicit measures have offered evidence for their convergent and discriminant validity in dif-ferent scenarios and groups [44,45], with research to date finding that implicit indices appear to be better than self-report or clinical judge-ment at predicting important clinical behaviors such as suicide at-tempts [46], substance misuse [47], and sexual offending [48].

Very few previous studies have used measures of implicit cognition in patients with PNESs. One prior study compared covert attitudes toward sickness in patients with PNESs, patients with epilepsy, and controls using an Implicit Association Test that examined responses to pairings of sickness-related words and pleasant words [49]; however, there were no significant group differences in implicit attitudes toward sick-ness despite differences in reports of clinical symptoms (e.g., greater so-matic complaints in those with PNESs versus those with epilepsy). Other studies found that individuals with PNESs do have implicit biases com-pared with healthy controls in that they show greater emotional arousal to neutral stimuli [50] and direct greater preconscious attention toward threat cues (angry faces; [51]). Therefore, it is possible that individuals with PNESs have a greater underlying - or implicit - sense of anxiety.

One contemporary measure of implicit cognition is the Implicit Rela-tional Assessment Procedure (IRAP; [43]). The IRAP involves presenting (frequent word) stimuli with specific 'relational terms' (e.g., true, false, same, and opposite) so that the relationships between the presented stimuli (termed verbal relations) can be assessed. For example, partici-pants may be shown a statement such as 'I am — anxious' or 'Others are anxious' and asked to confirm or deny this relationship (in this example by choosing the term 'true' or 'false'). Importantly, participants are asked to respond quickly and accurately to these statements in ways that, depending on the trial type, are consistent or inconsistent with their beliefs. In the present study, for example, participants were asked to deny being anxious during consistent trials (e.g., selecting 'false' to the stimuli 'I am - anxious') and to endorse the opposite during inconsistent trials (e.g., selecting 'true' to the stimuli 'I am - anxious'). The methodology is predicated on the assumption that the strength of specific implicit verbal relations is reflected in the participant's response times; more simply, the basic IRAP principle is that average response latencies are relatively shorter across trials consistent with the participant's "true" (implicit) beliefs (e.g., those statements that cohere with the participant's implicit verbal relations) compared with trials in-consistent with their beliefs.

A wealth of studies have demonstrated the IRAP effect, providing support for its utility and reliability as an implicit measure (see [52] for an overview). Furthermore, research has indicated that the IRAP compares favorably with other implicit measures of individual differ-ences [53], is perhaps less susceptible to 'faking' or overt manipulation [54], and can target clinically relevant phenomena $[48,55]$.

\subsection{Aims and hypotheses}

The research outlined above suggests that anxiety and experiential avoidance may play a key part in PNESs. Specifically, this study aimed to (1) compare individuals with PNESs, individuals with epilepsy, and nonclinical controls on implicit and explicit measures of anxiety;(2) examine discrepancies between implicit and explicit anxiety within these groups; (3) examine correlations between anxiety and avoidance in PNESs; and (4) establish whether these measures of anxiety or avoidance have predictive utility in differentiating diagnostic groups. It was hypothesized that patients with PNESs would report higher levels of (explicit) anxiety and experiential avoidance compared with those with epilepsy or controls. However, previous studies have also highlighted that patients with PNESs are more likely than those with epilepsy to deny the relevance of psychological factors for their seizures [56], and, therefore, we predicted that those with PNESs would show greater implicit anxiety and show greater discrepancies between im-plicit and explicit anxiety (i.e., greater implicit relative to explicit anxiety) compared with those with epilepsy or controls.

\section{Method}

\subsection{Participants}

Thirty adults with PNESs and 25 adults with epilepsy (13 with focal epilepsy, 5 with idiopathic generalized epilepsy, and 7 with unclassifi-able epilepsy) were recruited from outpatient seizure clinics at the Sheffield Teaching Hospital NHS Foundation Trust between February and September 2012. All diagnoses were made by neurologists special-izing in the treatment of seizures, and only those whose diagnoses were supported by a previous video-EEG recording of a typical seizure were included. Patients with mixed seizure disorders (epilepsy and PNESs) were excluded. Thirty-one adults with no reported history of seizures were recruited through an advertisement and served as a nonclinical control group. All participants were at least 18 years old. Individuals unable to complete self-report questionnaires unaided, not fluent in English, and physically unable to a use a computer were excluded.

\subsection{Ethical approval}

The research was approved by both the Leeds Research and Ethics Committee (REC) and the Research Office of the Sheffield Teaching 
Hospitals NHS Foundation Trust. All participants provided written in-formed consent in accordance with REC guidance and Helsinki Good Clinical Practice.

\subsection{Procedure}

This was a prospective study; participants were informed that the study was looking at differences in unconscious thinking prior to consenting and initially completed a brief demographic questionnaire before proceeding to the self-report measures outlined below. The order of the questionnaires was randomized using an online research randomizer (available from http:// www.randomizer.org). Following the completion of these measures, participants completed an IRAP pro-cedure designed for the present study (detailed further below). Asses-sors were not blinded to diagnosis; however, participants completed the questionnaires independently and separate from assessors.

\subsubsection{Demographic and medical history}

Basic demographic information (age, gender, and level of education), seizure diagnosis, and seizure frequency were self-reported. Partici-pants were also asked to specify in an open-ended fashion whether they had any current or previous mental health problems.

\subsubsection{Spielberger State-Trait Anxiety Inventory (STAI)}

The STAI is an explicit self-report measure of state and trait anxiety [57]. It is composed of 40 questions with response options ranging from 1 (not at all/ almost never) to 4 (very much so/almost always) on a Likert-type scale. This produces two subscale raw scores ranging from 20 to 80 , with higher scores reflecting higher levels of either state or trait anxiety. The STAI was chosen because of its ability to examine both state and trait constructs with test-retest reliability of .40 and .86 , respectively. It also has concurrent validity with other measures of anxiety having correlations around .80 [58]. The Cronbach alpha scores for the state and trait measures in this study were .93 and .95 , respectively. The state measure of the STAI has also been used as a screening tool for mental disorders in general, with an optimal cutoff score of 54/55 for an accuracy of 87 [59].

\subsubsection{Patient Health Questionnaire (PHQ-15)}

The PHQ-15 was used as a screening tool for somatization and so-matic symptoms [60]. The measure comprises 15 somatic symptoms; each scored either 0 ("not bothered at all"), 1 ("bothered a little"), or 2 ("bothered a lot"). Total scores range from 0 to 30 and are classified as reflecting minimum (0-4), mild (5-9), moderate (10-14), or severe $(15+)$ somatization. The measure was not developed as a standalone diagnostic tool but used to supplement other clinical information. The PHQ-15 has good internal consistency (Cronbach's alpha of .80) and moderate associations between items [60]. The test-retest reliability is moderate with a $\kappa$ coefficient of .60 [61].

\subsubsection{Multidimensional Experiential Avoidance Questionnaire (MEAQ)}

Experiential avoidance was measured with the MEAQ [62]. This selfreport questionnaire asks participants to indicate the extent to which they agree or disagree with 62 statements (e.g., "When nega-tive thoughts come up, I try to fill my head with something else") on a 6-point Likert scale from 1 (strongly disagree) to 6 (strongly agree). Total scores range from 62 to 372, with a higher score equating to higher endorsement of avoidance-related statements. Aspects of experiential avoidance measured by the MEAQ include the following: behavioral avoidance, distress aversion, procrastination, distraction and suppres-sion, repression and denial, and distress endurance. The alpha for the total MEAQ score is excellent (.91-.92) with average interitem correla-tion in the low to moderate range (.15) reflecting the multidimensional nature of the questionnaire and indicating its assessment of a broader range of content compared with other measures of experiential avoid-ance. In this study, the Cronbach alpha was .91 for the overall scale.

\subsubsection{Implicit Relational Assessment Procedure (IRAP)}

An IRAP which aimed to specifically target implicit anxiety was developed by the authors $\left(\operatorname{IRAP}_{\mathrm{ANX}}\right)$. The stimulus set for the $\operatorname{IRAP}_{\mathrm{ANX}}$ was designed to reflect the dimensions of the STAI (Table 1), with stimuli and response options presented and recorded by the IRAP soft-ware (available from irapresearch.org). One of two category labels ("I am" or "Others are") was presented on each trial, with a single target stimulus taken from two sets of stimuli: one set of target stimuli contained anxious terms (e.g., anxious) and the other their semantically opposite terms (e.g., calm). Two response options ("true" or "false") were also presented on each trial. During consistent trials, participants were required to confirm that they were calm and to deny being anxious; during inconsistent trials, these response requirements were reversed.

The IRAP task was presented on a portable laptop computer. Partic-ipants read through instructions presented visually with the experi-menter (see appendix A). These instructions explained the IRAP procedure and how to complete the task and highlighted that accuracy and speed in responding were a prerequisite to progress to the test phase. Participants were specifically informed that it would sometimes be necessary to respond to the stimuli in a manner consis-tent with their beliefs and sometimes in ways that may be inconsistent with their beliefs. Participants were instructed to derive the correct response style for each block of trials but were not told which trials were considered to be consistent or inconsistent. To ensure under-standing of the task and minimize random responding, each participant was administered at least two practice blocks until they achieved an average response time of less than $3 \mathrm{~s}$ and an accuracy rating above $80 \%$ (in line with previous research [48]).

Each trial comprised a category label ("I am" or "Others are") appearing at the top of the screen, with one of 12 target words in the center (e.g., "anxious", "worried", and "calm") and the two response options "true" and "false" in the bottom corners. All of the stimuli (label, target, and response options) were presented simultaneously (Fig. 1) and remained on the screen until the participant selected one of the relational terms by pressing the ' $\mathrm{D}$ ' key for 'true' or the ' $\mathrm{K}$ ' key for 'false'. Choosing the relational term deemed "correct" for a particular trial removed all stimuli from the screen for $400 \mathrm{~ms}$ before the next trial was presented. Choosing the relational term that was deemed "incorrect" for that particular trial produced a red " $\mathrm{X}$ " in the center of the screen. To remove the $X$ and proceed to the 400 -millisecond inter-trial interval, participants were required to select the correct response option.

An accurate response was dependent on whether a consistent or inconsistent trial was administered. During consistent blocks of the

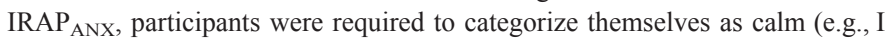
am - Calm - True and I am - Anxious - False) and others as anx-ious (e.g., Others are - Anxious - True and Others are - Calm — False). During inconsistent blocks, the response contingencies were reversed. Fig. 1 illustrates the two category labels with their respective consistent and inconsistent stimuli.

During the IRAP, participants were exposed to six test blocks, alter-nating between consistent and inconsistent blocks, each with 24 trials.

Table 1

The stimulus arrangements for the $\operatorname{IRAP}_{\mathrm{ANX}}$.

\begin{tabular}{lll}
\hline Sample 1: I am & & Sample 2: Others are \\
\cline { 1 - 1 } Response option 1: true & & Response option 2: false \\
\cline { 1 - 1 } Target stimuli consistent with sample 1 & & Target stimuli consistent with sample 2 \\
\hline Calm & & Tense \\
Relaxed & Nervous \\
Rested & Anxious \\
Secure & Scared \\
Laid-back & Afraid \\
\hline
\end{tabular}



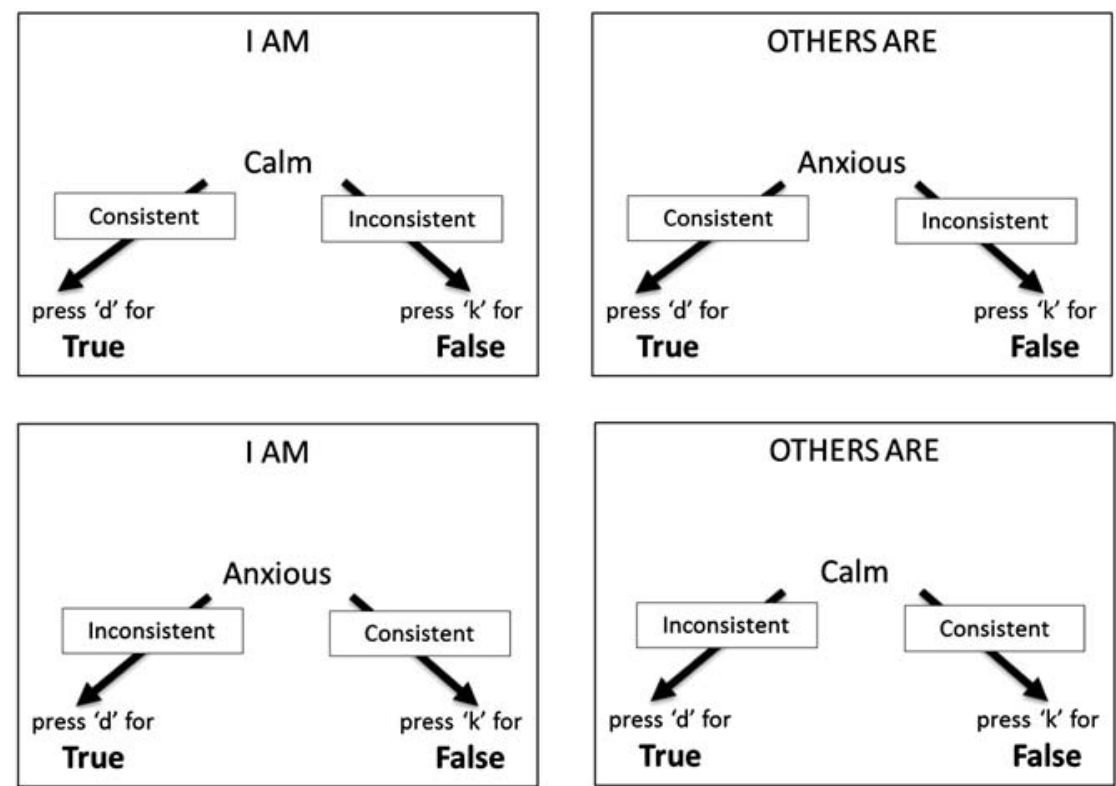

Fig. 1. Examples of the four trial types in the $\mathrm{IRAP}_{\mathrm{ANX}}$. Arrows with text boxes showing responses consistent/inconsistent did not appear onscreen and are shown for illustrative purposes only.

The category label and target stimuli within each block were random-ized with the constraint that stimuli were not presented more than three times with each sample. Visual instructions after each test block indicated that the next block would involve reversing the previously correct and incorrect responses. Once the final block was completed, participants were thanked and debriefed.

\subsection{IRAP data preparation}

Raw latency data from the IRAP (time in milliseconds from trial onset to participant response) were converted into a D measure (D-IRAP), consistent with current implicit measure research outlined by Barnes-Holmes and colleagues [63]. The D transformation serves to minimize the impact of individual variability relating to extraneous variables such as age, cognitive ability, and/or motor skills offering a cleaner response latency measurement [64]. D scores are relative to re-sponse latency differences with larger scores indicating greater differ-ences in response latencies between consistent and inconsistent trials. Implicit Relational Assessment Procedure raw scores were transformed into five D-IRAP scores: one for each of the four trial types and an overall D-IRAP effect score (mean of the four trial-type scores). Positive scores reflect responding in line with preexperimentally determined consis-tent items (in the current study: self as calm and others as anxious) and negative scores reflect the reverse (i.e., self as anxious and others as calm). Table 2 details the conversion procedure of the raw latency data. To facilitate interpretation of the results and comparability with explicit measures, the computed self-trial D-IRAP scores were reverse-scored prior to statistical analysis. Consequently, in analyses reported below, positive scores are indicative of anxiety (response tendency toward self as anxious), and negative scores reflect the reverse (self as calm). Implicit anxiety scores are, thus, tuned in the same direction as explicit anxiety scores: i.e., higher positive scores indicative of greater anxiety.

\subsection{Statistical analysis}

Statistical analysis was completed with IBM SPSS for Windows version 20.0. The explicit measurement data (i.e., self-report measures of state anxiety, trait anxiety, somatic symptoms, and experiential avoidance) were analyzed using a multivariate analysis of variance (MANOVA). Specific predictions were tested using analysis of variance (ANOVA). Welch's adjusted $\mathrm{F}$ is reported where the assumption of homogeneity of variance was not met. Where significant differences were found, Tukey's HSD tests were used to determine where the differ-ences were and correct for multiple comparisons.

For the purpose of computing implicit-explicit discrepancy scores, all indices of self-referent anxiety (explicit trait, explicit state, and implicit selftrials) were first transformed into z-scores (enabling direct compa-rability) using the appropriate whole sample mean and SD. For example, individual trait anxiety z-scores were computed as: $z$-trait $=($ observed STAI trait score - Grand Mean STAI trait/Grand SD). Computed z-scores were then used to compute discrepancy scores by subtracting the

Table 2

The method for converting raw latency scores to the D-Implicit Relational Assessment Procedure (D-IRAP) scores.

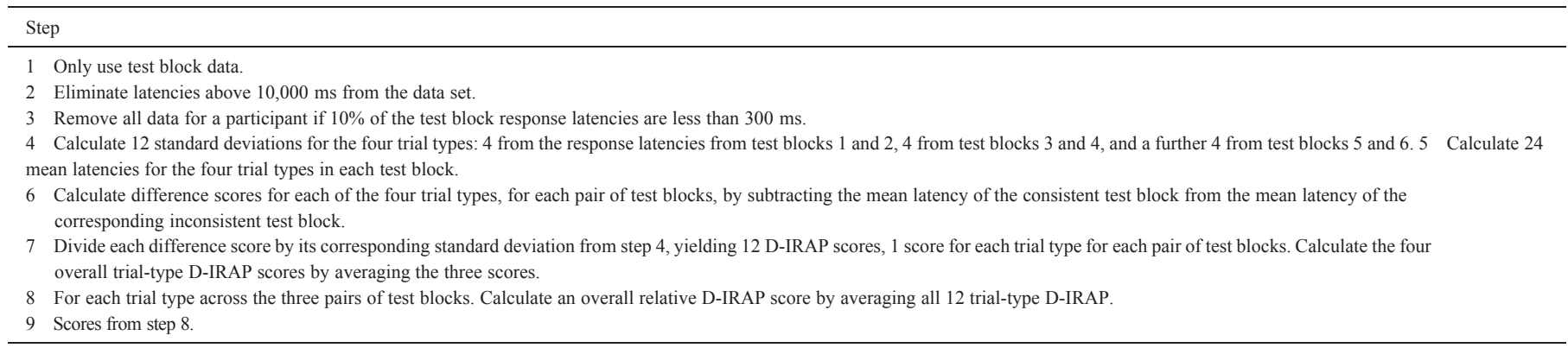


implicit z-score (z-transformed D-IRAP ${ }_{\mathrm{ANX}}$ self-trials) from the rele-vant explicit z-score (z-trait for trait discrepancy; z-state for state discrepancy). In this way, higher positive discrepancy scores were indic-ative of greater explicit relative to implicit anxiety. Transformed z-scores were only used in computation of the anxiety discrepancy scores; un-transformed scores were used in analyses of the variables from which these discrepancy scores were derived (preserving original scaling).

\section{Results}

\subsection{Demographics}

Groups were closely matched on the variables of gender, age, and education (ps N .05), as well as on self-reported seizure frequency ( $\mathrm{p} \mathrm{N} .05$ ) but differed significantly in relation to self-reported mental health problems ( $\mathrm{p}$ $=.021$, Fisher's exact test; see Table 3). Participants who self-reported having a mental health problem all stated that they experienced depression, an anxiety disorder, or both. The groups with PNESs and epilepsy did not differ significantly in terms of the proportion of patients above the STAI psychopathology cutoff.

\subsection{IRAP results}

Eight participants (3 with PNESs, 3 with epilepsy, and 2 controls) were unable to complete the IRAP tasks within the set criterion (median b3 s, N 80\% accuracy). Data from all other participants were retained fol-lowing the transformation of raw latencies into the D-IRAP scores. The self and other mean D-IRAP ${ }_{\text {ANX }}$ scores for the three groups $(\mathrm{N}=78)$ are presented in Fig. 2. The data show that all groups demonstrated a general bias toward self and others as calm (illustrated by negative scores).

A $3 \times 4$ mixed repeated analysis of variance (ANOVA) was conducted on the D-IRAP ${ }_{\mathrm{ANX}}$ scores, with diagnosis as the between-participants variable and trial type as the within-participant variable. There was a substantial effect for trial type, $\mathrm{F}(3,75)=30.85, \mathrm{p}$ b $.001, \eta_{\mathrm{p}}=.01$, with faster responding on the self-trials versus the other-trials. The analysis revealed no significant interaction between diagnosis and trial type, $\mathrm{F},(6,225)=.47, \mathrm{p}=.87, \eta_{\mathrm{p}}=.02$, with all groups demon-strating similar responses $\mathrm{F}(2,75)=.59, \mathrm{p}=.56, \eta_{\mathrm{p}}$ $=.02$. Four one-way between-participants ANOVAs were also used to conduct planned comparisons for each trial type. No significant effects were found

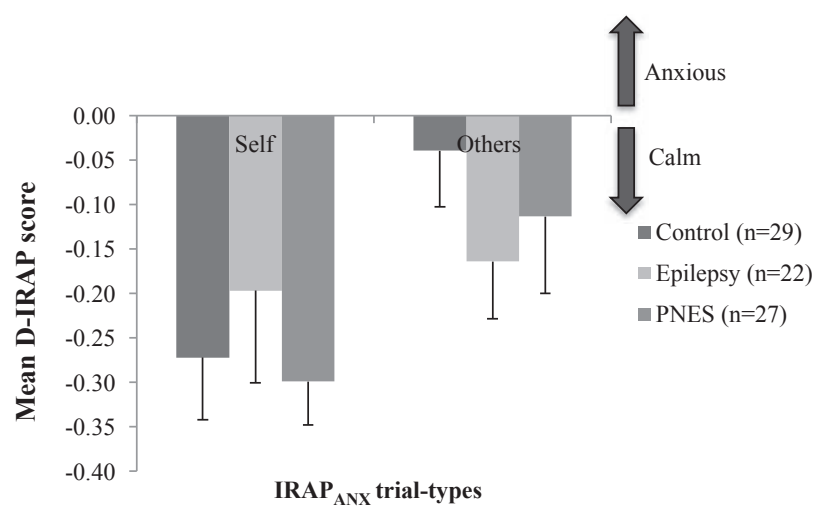

Fig. 2. Mean self and other D-IRAP $\mathrm{ANX}_{\mathrm{A}}$ scores.

( $\mathrm{p}$ values $\geq .47$ ). Contrary to our expectations, this suggests no differ-ences in implicit anxiety between the diagnostic categories.

\subsection{Explicit measures}

A one-way multivariate analysis of variance (MANOVA) was con-ducted with group as an independent variable and the four explicit measures (trait anxiety, state anxiety, somatization, and experiential avoidance) as dependent variables. There was a significant multivari-ate effect of group, Wilks' Lambda $=.49, \mathrm{~F}(8,160)=8.73, \mathrm{p} \mathrm{b} .001, \eta_{\mathrm{p}}=.30$. To determine which variable(s) differed between groups, a series of four one-way between-groups ANOVAs was carried out. To conservatively protect against multiple testing errors, the alpha criterion for these follow-up ANOVAs was adjusted using sequential Holm-Bonferroni correction (from smallest to largest observed $\mathrm{p}$ value, the threshold for significance of omnibus F statistics, thus, ranged from $p \mathrm{~b} .0125$ to $\mathrm{p}$ b .05).

There was a significant effect of group on trait anxiety, Welch's F $(2,54.5)$ $=6.17, \mathrm{p}=.004, \eta_{\mathrm{p}}=.15$. Tukey's HSD test indicated that the group with PNESs $(M=79.00, S D=50.10)$ s scored significantly higher compared with the control group $(\mathrm{M}=61.00, \mathrm{SD}=42.84)$. The group with epilepsy $(M=64.00, S D=38.23)$ did not differ significantly from either the control or the group with PNESs. Group differences did not reach significance for state anxiety, as measured by Spielberger's State-Trait Anxiety Inventory, F $(2,83)=$ $3.08, \mathrm{p}=.051, \eta_{\mathrm{p}}=.07$.

Table 3

Demographic and clinical data of the three groups.

\begin{tabular}{|c|c|c|c|c|}
\hline & $\begin{array}{l}\text { Controls } \\
(\mathrm{n}=31)\end{array}$ & $\begin{array}{l}\text { Epilepsy } \\
(\mathrm{n}=25)\end{array}$ & $\begin{array}{l}\text { PNESs } \\
(\mathrm{n}=30)\end{array}$ & $\mathrm{p}$ \\
\hline \multicolumn{5}{|l|}{ Gender $(\%)$} \\
\hline Females & $21(67.7)$ & $16(64.0)$ & $22(73.3)$ & \\
\hline Males & $10(32.3)$ & $9(36.0)$ & $8(26.7)$ & .75 \\
\hline Mean age (SD) & $42.97(13.93)$ & $39.40(16.49)$ & $40.87(12.88)$ & .65 \\
\hline \multicolumn{5}{|l|}{ Highest level of education (\%) } \\
\hline Secondary school & $6(19.4)$ & $4(16.0)$ & $8(26.7)$ & \\
\hline College/sixth-form & $10(32.3)$ & $9(36.0)$ & $12(40.0)$ & \\
\hline Diploma & $7(22.6)$ & $5(20.0)$ & $5(16.7)$ & \\
\hline UG degree & $7(22.6)$ & $2(8.0)$ & $4(13.3)$ & \\
\hline PG qualification & $1(3.2)$ & $5(20.0)$ & $1(3.3)$ & .43 \\
\hline \multicolumn{5}{|l|}{ Number reporting mental health problems (\%) } \\
\hline None & $23(74.2)$ & $17(68.0)$ & $14(46.7)$ & \\
\hline Past & $6(19.4)$ & $5(20.0)$ & $4(13.3)$ & \\
\hline Present & $2(6.5)$ & $3(12.0)$ & $12(40.0)$ & .02 \\
\hline Number above STAI psychopathology cutoff (\%) & $1(3.2)$ & $2(8.0)$ & $7(23.3)$ & .16 \\
\hline \multicolumn{5}{|l|}{ Number of seizures reported per month } \\
\hline Mean (SD) & - & $4.38(7.48)$ & $7.36(7.45)$ & \\
\hline Median (IQR) & - & $1.0(0.0-7.3)$ & $6.0(2.0-12.0)$ & .09 \\
\hline
\end{tabular}

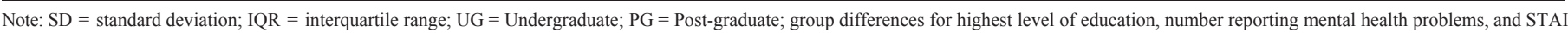
psychopathology cutoff were tested using Fisher's exact test to account for small cell sizes; gender was tested using a chi-squared test; seizure frequency was based on self-report estimates and tested using the Kruskal-Wallis test. 
There was a significant difference between the three groups on reported somatic symptoms, as measured by the PHQ15; Welch's F $(2,52.49)=$ $29.21, \mathrm{p} \mathrm{b} .001, \eta_{\mathrm{p}}=.49$. Tukey's HSD test revealed that the group with PNESs $(\mathrm{M}=14.80, \mathrm{SD}=6.19)$ scored significantly higher compared with the control group $(\mathrm{M}=5.00, \mathrm{SD}=3.33)$ and the group with epilepsy $(\mathrm{M}=6.60, \mathrm{SD}$ $=3.46$ ). The group with epilepsy and the control group did not significantly differ from each other.

Finally, there was a significant difference between the three groups on experiential avoidance (MEAQ total score); Welch's $F(2,54.07)=8.89, p$ b .001, $\eta_{\mathrm{p}}=.21$. Trukey's HSD test indicated that the group with PNESs $(\mathrm{M}=$ $235.50, \mathrm{SD}=48.86$ ) scored significantly higher com-pared with the control group $(M=190.03, S D=34.73)$ and the group with epilepsy $(M=198.68, S D$ $=33.37$ ). The group with epilepsy and the control group did not differ significantly from each other.

Overall, consistent with expectations, the group with PNESs scored significantly higher compared with the healthy control group and the group with epilepsy on somatization and experiential avoidance; the group with PNESs also scored significantly higher on trait anxiety compared with the control group (but not the group with epilepsy). Fig. 3 summarizes group scoring on the explicit measures and highlights significant differences.

\subsection{Implicit-explicit discrepancies}

To test the hypothesis that there would be larger discrepancies between the implicit and explicit measures of anxiety in patients with PNESs, a one-way between-groups ANOVA was conducted. There was a statistically significant difference for the three groups in terms of discrepant anxiety, $F(2,75)=6.26$, $\mathrm{p}=.003, \eta_{\mathrm{p}}=.14$. Tukey's HSD test indicated that the group with PNESs had significantly larger discrepancies compared with the control group and the group with epilepsy, who did not differ significantly from each other. These dis-crepancies are illustrated in Fig. 4.

\subsection{Relationships between avoidance and anxiety}

Within-group relationships between experiential avoidance and anxiety/ somatization were examined using Pearson's correlations (see Table 4). For each set of correlations within each group (i.e., control, epilepsy, and PNESs), significance levels were adjusted for multiple testing using a sequential HolmBonferroni procedure. Table 4 high-lights both relationships that were only significant before adjusting the .05 alpha criterion for multiple testing $\left(^{*}\right)$ and relationships that

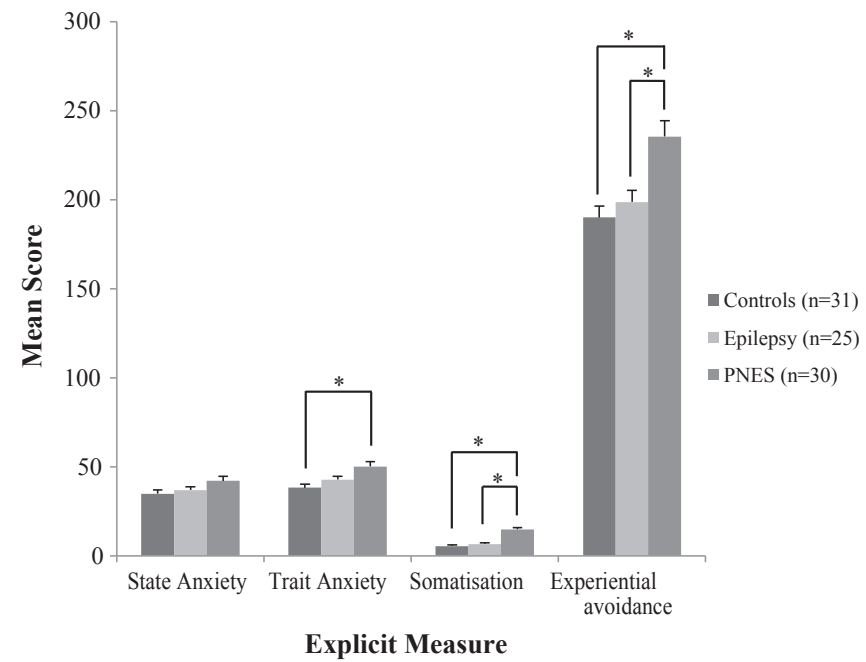

Fig. 3. Mean scores on each of the explicit self-report measures, with standard bars indi-cating one standard error; *p b .05.

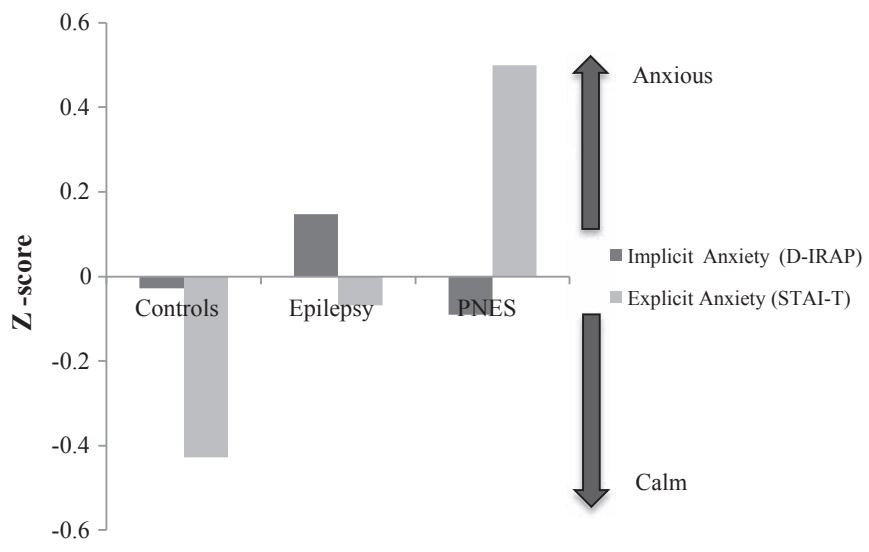

Fig. 4. Discrepancies between implicit and explicit anxiety.

remained significant after adjustment $(* *)$. Given the limited power within each group, it can be seen that only relationships with large effect-sizes (rs $\approx .50$ ) met adjusted criteria for significance.

After adjustment, avoidance was positively associated with (1) higher explicit trait anxiety levels and (2) greater discrepancy scores be-tween (high) explicit trait anxiety and relatively (low) implicit anxiety in the group with PNESs. No significant relationships were found be-tween avoidance and implicit anxiety scores in the group with PNESs (ps N .16), and none of the relationships were significant for the group with epilepsy or the control group.

\subsection{Psychological factors and seizure frequency}

The relationship between state and trait anxiety, experiential avoid-ance, and somatization and seizure frequency was investigated using Spearman's rank order correlations (Table 5). For each family of tests (correlations within each group and comparative Fisher $\mathrm{Z}$ tests), signif-icance levels were adjusted for multiple testing using a sequential Holm-Bonferroni procedure as before.

In the group with epilepsy, there were no significant correlations between seizure frequency and any of the psychological measures. In the group with PNESs, there were strong positive correlations between seizure frequency and trait anxiety, implicit anxiety, and avoidance.

\subsection{Predicting diagnosis}

As somatization (PHQ-15) and experiential avoidance (MEAQ) were significantly higher in the group with PNESs compared with the group with epilepsy, these were analyzed by using univariate binary logistic regression to assess how well they predicted diagnoses. The full model containing both predictors was statistically significant, $\chi^{2}(3, \mathrm{~N}=55)=32.05 \mathrm{p} \mathrm{b} .001$, indicating that the model could

Table 4

Correlations with experiential avoidance.

\begin{tabular}{lccc}
\hline & Controls & Epilepsy & PNESs \\
\hline State anxiety & & & \\
$\quad$ Explicit & -.05 & .02 & $.41^{*}$ \\
$\quad$ Explicit-implicit & -.09 & .10 & .27 \\
Trait anxiety & & & \\
$\quad$ Explicit & .09 & .20 & $.63^{* *}$ \\
$\quad$ Explicit-implicit & .00 & .24 & $.49^{* *}$ \\
Somatization & .10 & & .18 \\
Implicit anxiety & & -.10 & .16 \\
$\quad$ Self D-IRAP & .10 &
\end{tabular}

* Indicates $\mathrm{r}$ values that are significant at the unadjusted $\mathrm{p} \mathrm{b} 0.05$ level.

** Indicates $r$ values that remain significant following Holm-Bonferroni correction for multiple testing (all ps b .01) 
Correlations with seizure frequency.

\begin{tabular}{|c|c|c|c|}
\hline & $\begin{array}{l}\text { Group with } \\
\text { epilepsy }\end{array}$ & $\begin{array}{l}\text { Group with } \\
\text { PNESs }\end{array}$ & $\begin{array}{l}\text { Test of difference: } \\
\text { Fisher Z }\end{array}$ \\
\hline \multicolumn{4}{|l|}{ State anxiety } \\
\hline Explicit & -.06 & .36 & -1.52 \\
\hline Explicit-implicit & -.07 & -.16 & 0.32 \\
\hline \multicolumn{4}{|l|}{ Trait anxiety } \\
\hline $\begin{array}{l}\text { Explicit Explicit- } \\
\text { implicit }\end{array}$ & $\begin{array}{l}-.03 \\
-.04\end{array}$ & $\begin{array}{l}.67^{* *} \\
.16\end{array}$ & $\begin{array}{l}-2.93^{* *} \\
-0.42\end{array}$ \\
\hline Somatization & .34 & .38 & -0.16 \\
\hline $\begin{array}{l}\text { Experiential avoidance } \\
\text { Implicit anxiety }\end{array}$ & -.02 & $.55^{* *}$ & $-2.22^{*}$ \\
\hline Self D-IRAP ${ }_{\mathrm{ANX}}$ & .09 & $.56^{* *}$ & -1.89 \\
\hline
\end{tabular}

predict individuals with either PNESs or epilepsy. The model was able to explain between $44.2 \%$ (Cox and Snell R square) and 59.1\%(Nagelkerke R square) of the variance in diagnosis and correctly classi-fied $83.6 \%$ of the cases $(84.0 \%$ sensitivity and $83.3 \%$ specificity). As shown in Table 6 , both somatic symptoms and avoidance made a unique statistically significant contribution to the model. The addition of implicit anxiety scores did not improve the model significantly.

\section{Discussion}

The current study aimed to examine implicit and explicit anxiety in people with PNESs, explore the relationship with experiential avoidance and PNES frequency, and determine whether they could be useful in dis-criminating between people with PNESs and epilepsy.

In line with previous findings, individuals diagnosed with PNESs or epilepsy self-reported significantly higher levels of anxiety compared with nonclinical controls [28]. However, no significant differences were found between the two clinical groups themselves. The group with PNESs endorsed significantly more somatic complaints compared with both the group with epilepsy and the healthy control group, as well as reported significantly higher levels of experiential avoidance con-sistent with previous findings [2,65]. Frequency of PNESs was strongly correlated with explicit anxiety scores and experiential avoidance; how-ever, consistent with some previous reports [66] but in contrast with others [67], psychological factors as measured in the present study were unrelated to the frequency of epileptic seizures within the group with epilepsy.

Uniquely, this study also examined implicit anxiety in people with PNESs. In contrast to our expectations, we found no clear differences be-tween patients with PNESs and those with epilepsy or healthy controls in terms of implicit anxiety. Importantly, however, we did detect signif-icantly larger discrepancies in implicit and explicit anxiety scores in the group with PNESs compared with the two comparison groups. What is more, there was a strong positive correlation between implicit anxiety scores and PNES (but not epileptic seizure) frequency. These novel findings are discussed in more detail below.

Table 6

Logistic regression predicting diagnosis.

\begin{tabular}{lcccccc}
\hline & B & SE & Wald & Odds ratio & $\begin{array}{l}\text { 95\% CI for } \\
\text { odds ratio }\end{array}$ \\
\hline Somatization & .32 & .09 & $11.89^{* *}$ & 1.34 & & \multicolumn{2}{l}{$\begin{array}{l}\text { Lower upper } \\
\text { Experiential avoidance }\end{array}$} & .02 & .01 & $8.77^{* *}$ & 1.02 & 1.00 & 1.65 \\
\hline
\end{tabular}

Note: $\mathrm{CI}=$ confidence interval.

** p b . 01 .

\subsection{Anxiety}

The current findings suggest that individuals with PNESs may not hold automatic or unconscious perceptions of themselves as anxious, despite reporting more anxiety than control participants on explicit measures. One interpretation of these results is based on the dual-attitude model formulated by Wilson and colleagues that suggests that implicit measures reflect older, habitual cognition [68]. A profile of low-implicit high-explicit anxiety could, therefore, be reflective of individuals who have become anxious later in life; in populations with PNESs, this may relate to explicit anxiety developing following the onset of the seizures themselves. However, a more plausible explana-tion for this pattern might be that the dissociation associated with PNESs themselves (combined with wider avoidance tendencies in a patient's life in between seizures) effectively stop patients from holding implicit anxious cognitive biases which they might have developed in the absence of PNESs. Consequently, those with PNESs may explicitly report anxiety while failing to "internalize" anxiety as part of their self-concept. Such a "protective" function of PNESs could also help explain the observation that patients with PNESs report more negative life events compared with those with epilepsy but fail to make a link be-tween these life events and their seizures [4] or that a large subgroup of patients with PNESs are limited in their emotional and psychological awareness [69].

Despite the fact that the group with PNESs was characterized by a discrepancy between low-implicit anxiety and high-explicit anxiety, we found a strong correlation between greater implicit anxiety and higher PNES frequency. It is possible that this finding reflects the psycho-pathological heterogeneity of PNESs: previous studies have identified at least two major groups characterized by low and high levels of emo-tional dysregulation [70]. Psychogenic nonepileptic seizures may be linked to implicit anxiety in some and explicit anxiety in other patients.

A previous study in a nonpatient population demonstrated that im-plicit anxiety predicted cardiovascular responses (i.e., heart rate and blood pressure) to threat above and beyond explicit measures [71]. Im-portantly, the authors of this study highlighted that implicit anxiety only predicted cardiovascular responses to acutely stressful events rather than cardiovascular responding more generally. Nevertheless, given that it predicted responses measured at later points in time, they suggest that implicit anxiety has a "trait"-like influence on behavior. Pre-vious studies have demonstrated that PNESs are associated with similar heart rate variability (HRV) changes to those seen in acute stress [72]. Future studies could explore to what extent implicit anxiety and seizure frequency relate to such physiological responses in this patient group.

This study is the first to show a relationship between self-reported trait anxiety and PNES frequency. While the strong positive correlation does not allow us to draw definite conclusions about the direction of the relationship, the fact that trait rather than state anxiety was correlated with PNES frequency supports previous suggestions that anxiety plays an important etiological role in PNESs $[65,73]$. A variety of psychological theories can be applied to account for the proposed relationship be-tween PNESs and anxiety; psychodynamic theories, for example, con-ceptualize anxiety as the by-product of an intrapsychic conflict and propose that PNESs can be a symptom of that conflict [74]. Behavioral models of human functioning (e.g., [75]) can also be adapted to explain the observed relationship between anxiety and PNESs in terms of condi-tioned responses and reinforcement history; such theories postulate that anxiety is a conditioned response to a threat or trigger (e.g., a flash-back or a familial conflict) and that PNESs consequently function as a negatively reinforcing response to threat and anxiety, perpetuating their occurrence in threat-inducing situations [76].

\subsection{Experiential avoidance}

As expected, as well as in line with previous research, individuals with PNESs reported higher levels of avoidance compared with those 
with epilepsy $[7,9,65,77]$. The results of this study extend prior research by highlighting the idea that it is especially emotional experience that people with PNESs work to avoid, including greater avoidance of painful and uncomfortable feelings, emotional disconnection, and believing that negative emotions are damaging.

In the current sample, experiential avoidance did not correlate with somatic symptoms. However, avoidance was strongly correlated with selfreported seizure frequency in the group with PNESs. The present study, therefore, is consistent with the idea that experiential avoidance (perhaps as an "overlearned" or practiced response style) may be a risk factor for the development of PNESs. Similarly, Myers and colleagues [69] found that reports of alexithymia, which refers to a lack of emo-tional awareness and expression, did not differ between PNESs and epilepsy but that within the group with PNESs, alexithymia was associ-ated with anxious arousal and avoidance.

Finally, we observed a strong positive correlation between discrep-ant implicit-explicit anxiety scores and experiential avoidance. Recent studies on implicit cognition have conceptualized such discrepancies from within a cognitive dissonance theory perspective [78], suggesting that aversive dissonance-related discomfort increases when implicit and explicit beliefs diverge [79]. The application of cognitive dissonance theory to PNESs may, therefore, suggest that nonepileptic seizures function to reduce cognitive dissonance, and targeting this dissonance (e.g., using strategies from dialectical behavior therapy (DBT; [80])), is an avenue for future research and treatment approaches in populations with PNESs.

\subsection{Implications}

Recent developments in screening measures aimed at facilitating the differential diagnosis of epilepsy and PNESs are promising [81]. The re-sults presented here suggest that the inclusion of avoidance scales may enhance the predictive utility of such tools. The information provided by patients on such measures may also aid health professionals in devel-oping formulations and intervention plans and evaluating outcomes.

Cognitive behavioral therapy (CBT) and psychodynamic therapy are the leading published psychological interventions effective for PNESs [8286]. Our findings support the idea that increasing tolerance of unpleasant emotions and reducing maladaptive avoidant behavior patterns might represent mechanisms of change in these approaches. Therapies which directly target experiential avoidance, such as accep-tance and commitment therapy (ACT), or DBT (which also addresses cognitive dissonance, as noted above [80]), may be useful in augment-ing treatment for patients with PNESs [87].

\subsection{Limitations}

There are a number of limitations within the current study that require acknowledgment. Patients were only recruited to the study if they had a firm diagnosis, but the amount of time for which they had been experiencing seizures, any formal psychiatric diagnosis, or whether they were prescribed any psychotropic medication or anti-epileptic drugs were not recorded. The fact that many patients had a chronic seizure disorder means that it is more difficult to draw conclu-sions about the direction of the relationship between the psychological variables and PNESs. In addition, only the relationship between psycho-logical variables and seizure frequency was explored; one previous study showed that seizure severity was a predictor of psychological variables in epilepsy [66], and, therefore, future studies may want to consider the role of both severity and frequency. Moreover, this study was conducted with patients with seizures receiving current outpatient neurology care; it is, therefore, uncertain to what extent the results can be generalized to other patient groups.

In terms of methodology, the IRAP stimuli were developed specifical-ly to reflect dimensions of the explicit anxiety scale used in the study. The term 'others are' was used to avoid double negatives (e.g., I am not anxious - false), which can be problematic in IRAP research, but this rewording may have not been as effective in capturing people's beliefs about themselves in relation to others. Although there was no indication that our measure was ineffective in this population, it is nevertheless possible that there are differences in implicit cognition in people with PNESs that the IRAP did not successfully detect. The results of implicit assessments depend on the specific stimuli presented. It is important that the stimuli used are salient to the individual completing the measure and relate to the phenomena of interest. For example, nonword stimuli, or words based on other conceptualizations of anxiety, may have yielded different results.

Finally, this study did not use blinded assessors or implement any scales of effort or social desirability, and while it seems unlikely that differences in explicit anxiety were due to exaggerated responses, it is possible that the results were due to a response bias [88].

\section{Conclusion}

In conclusion, this study found significant differences between peo-ple with PNESs, those with epilepsy, or those without a history of sei-zures in terms of experiential avoidance and explicit (self-reported) anxiety, as well as significant relationships between PNES frequency with implicit anxiety, explicit anxiety, and experiential avoidance. While there were greater implicit versus explicit anxiety discrepancies in the group with PNESs, implicit anxiety levels did not differ between the three groups. These findings support various psychological models of PNESs and offer a rationale for psychological treatments targeting avoidant behavior patterns or cognitive dissonance.

\section{Acknowledgments}

Many thanks are due to all the participants who contributed to the study. We also thank Professor Paschal Sheeran for his advice on the study design.

\section{References}

[1] Reuber M, Monzoni C, Sharrack B, Plug L. Using interactional and linguistic analysis to distinguish between epileptic and psychogenic nonepileptic seizures: a prospec-tive, blinded multirater study. Epilepsy Behav 2009;16(1):139-44.

[2] Reuber M. Somatization, dissociation and general psychopathology in patients with psychogenic non-epileptic seizures. Epilepsy Res 2003;57(2-3):159-67.

[3] Schachter SC, LaFrance Jr WC, editors. Gates and Rowan's nonepileptic seizures with DVD. 3rd ed. Cambridge University Press; 2010 [370 pp.].

[4] Stone J, Binzer M, Sharpe M. Illness beliefs and locus of control: a comparison of patients with pseudoseizures and epilepsy. J Psychosom Res 2004;57(6):541-7.

[5] Mökleby K, Blomhoff S, Malt UF, Dahlström A, Tauböll E, Gjerstad L. Psychiatric comorbidity and hostility in patients with psychogenic nonepileptic seizures com-pared with somatoform disorders and healthy controls. Epilepsia 2002;43(2):193-8.

[6] Jawad SSM, Jamil N, Clarke EJ, Lewis A, Whitecross S, Richens A. Psychiatric morbidity and psychodynamics of patients with convulsive pseudoseizures. Seizure 1995;4(3):201-6.

[7] Goldstein LH, Drew C, Mellers J, Mitchell-O'Malley S, Oakley DA. Dissociation, hypnotizability, coping styles and health locus of control: characteristics of pseudoseizure patients. Seizure 2000;9(5):314-22.

[8] Cragar DE, Berry DTR, Schmitt FA, Fakhoury TA. Cluster analysis of normal personality traits in patients with psychogenic nonepileptic seizures. Epilepsy Behav 2005;6(4):593-600.

[9] Bakvis P, Spinhoven P, Zitman FG, Roelofs K. Automatic avoidance tendencies in pa-tients with psychogenic non epileptic seizures. Seizure - Eur J Epilepsy 2011;20(8): 628-34. 
[10] Myers L, Fleming M, Lancman M, Perrine K, Lancman M. Stress coping strategies in patients with psychogenic non-epileptic seizures and how they relate to trauma symptoms, alexithymia, anger and mood. Seizure 2013;22(8):634-9.

[11] Tull MT, Gratz KL, Salters K, Roemer L. The role of experiential avoidance in posttraumatic stress symptoms and symptoms of depression, anxiety, and somatization. J Nerv Ment Dis 2004;192(11):754-61.

[12] Kashdan TB, Barrios V, Forsyth JP, Steger MF. Experiential avoidance as a generalized psychological vulnerability: comparisons with coping and emotion regulation strat-egies. Behav Res Ther 2006;44(9):1301-20.

[13] Kashdan TB, Morina N, Priebe S. Post-traumatic stress disorder, social anxiety disorder, and depression in survivors of the Kosovo War: experiential avoidance as a contributor to distress and quality of life. J Anxiety Disord 2009;23(2):185-96.

[14] Hayes SC, Wilson KG, Gifford EV, Follette VM, Strosahl K. Experiential avoidance and behavioral disorders: a functional dimensional approach to diagnosis and treatment. J Consult Clin Psychol 1996;64(6):1152-68.

[15] Roberts NA, Reuber M. Alterations of consciousness in psychogenic nonepileptic sei-zures: emotion, emotion regulation and dissociation. Epilepsy Behav 2014;30:43-9.

[16] Seligman M. Abnormal psychology. Revised ed. W. W. Norton \& Co.; 2001 [864 pp.].

[17] Beck AT, Clark DA. An information processing model of anxiety: automatic and stra-tegic processes. Behav Res Ther 1997;35(1):49-58.

[18] Underwood G. Implicit cognition. New York, NY, US: Oxford University Press; 1996 [305 pp.].

[19] Gawronski B, Payne BK, editors. Handbook of implicit social cognition: measure-ment, theory, and applications. Guilford Press; 2010 [626 pp.].

[20] Greenwald AG, Banaji MR, Rudman LA, Farnham SD, Nosek BA, Mellott DS. A unified theory of implicit attitudes, stereotypes, self-esteem, and self-concept. Psychol Rev 2002;109(1):3-25.

[21] Vater A, Schröder-Abé M, Schütz A, Lammers C-H, Roepke S. Discrepancies between explicit and implicit self-esteem are linked to symptom severity in borderline per-sonality disorder. J Behav Ther Exp Psychiatry 2010;41(4):357-64.

[22] Reuber M, Pukrop R, Bauer J, Derfuss R, Elger CE. Multidimensional assessment of personality in patients with psychogenic non-epileptic seizures. J Neurol Neurosurg Psychiatry 2003;75(5):743-8.

[23] Direk N, Kulaksizoglu IB, Alpay K, Gurses C. Using personality disorders to distinguish between patients with psychogenic nonepileptic seizures and those with epileptic seizures. Epilepsy Behav 2012;23(2):138-41.

[24] Owczarek K, Jdrzejczak J. Personality profiles of patients with psychogenic nonepileptic seizures. In: Stevanovic D, editor. Epilepsy - Histological, Electroen-cephalographic and Psychological Aspects [Internet]. InTech; 2012 [[cited 2012 Jul 25]. Available from: http:// www.intechopen.com/books/epilepsy-histological-electroencephalographic-andpsychological-aspects/personality-profiles-of-patients-with-psychogenic-non-epilepticseizures].

[25] Tellez-Zenteno JF, Patten SB, Jetté N, Williams J, Wiebe S. Psychiatric comorbidity in epilepsy: a population-based analysis. Epilepsia 2007:48(12):2336-44.

[26] Galimberti CA, Ratti MT, Murelli R, Marchioni E, Manni R, Tartara A. Patients with psychogenic nonepileptic seizures, alone or epilepsy-associated, share a psycholog-ical profile distinct from that of epilepsy patients. J Neurol 2003;250(3):338-46.

[27] Bewley J, Murphy PN, Mallows J, Baker GA. Does alexithymia differentiate between patients with nonepileptic seizures, patients with epilepsy, and nonpatient controls?Epilepsy Behav 2005;7(3):430-7.

[28] Hixson JD, Balcer LJ, Glosser G, French JA. Fear sensitivity and the psychological profile of patients with psychogenic nonepileptic seizures. Epilepsy Behav 2006;9(4):587-92.

[29] Owczarek K. Anxiety as a differential factor in epileptic versus psychogenic pseudoepileptic seizures. Epilepsy Res 2003;52(3):227-32.

[30] Tojek TM, Lumley M, Barkley G, Mahr G, Thomas A. Stress and other psychosocial characteristics of patients with psychogenic nonepileptic seizures. Psychosomatics 2000;41(3):221-6.

[31] Wilkus RJ, Dodrill CB, Thompson PM. Intensive EEG monitoring and psychological studies of patients with pseudoepileptic seizures. Epilepsia 1984;25(1):100-7.

[32] Cragar DE, Schmitt FA, Berry DTR, Cibula JE, Dearth CMS, Fakhoury TA. A comparison of MMPI-2 decision rules in the diagnosis of nonepileptic seizures. J Clin Exp Neuropsychol 2003;25(6):793-804

[33] Bodde N, Brooks JL, Baker GA, Boon PAJM, Hendriksen JGM, Mulder OG, et al. Psycho-genic non-epileptic seizures - definition, etiology, treatment and prognostic issues: a critical review. Seizure 2009; 18(8):543-53.

[34] Banaji M. Implicit attitudes can be measured in the nature of remembering: essays in honor of Robert G. Crowder [Internet]; 2001 [[cited 2013 Jul 21]. Available from: http:// www.apa.org/pubs/books/431899A.aspx].

[35] Egloff B, Schmukle SC. Predictive validity of an implicit association test for assessing anxiety. J Pers Soc Psychol 2002;83(6):1441-55.

[36] Greenwald AG, Poehlman TA, Uhlmann EL, Banaji MR. Understanding and using the Implicit Association Test: III. Meta-analysis of predictive validity. J Pers Soc Psychol 2009;97(1):17-41.

[37] Brunel FF, Tietje BC, Greenwald AG. Is the Implicit Association Test a valid and valuable measure of implicit consumer social cognition? J Consum Psychol 2004;14(4): 385-

[38] Merikle PM, Reingold EM. Comparing direct (explicit) and indirect (implicit) measures to study unconscious memory. J Exp Psychol Learn Mem Cogn 1991;17(2):224-33.

[39] De Houwer J, Teige-Mocigemba S, Spruyt A, Moors A. Implicit measures: a normative analysis and review. Psychol Bull 2009;135(3):347-68.

[40] Moors A, De Houwer J. Automaticity: a theoretical and conceptual analysis. Psychol Bull 2006;132(2):297-326.

[41] Fazio RH, Olson MA. Implicit measures in social cognition research: their meaning and use. Annu Rev Psychol 2003;54(1):297-327.

[42] Greenwald AG, McGhee DE, Schwartz JLK. Measuring individual differences in im-plicit cognition: the implicit association test. J Pers Soc Psychol 1998;74(6):1464-80.
[43] Barnes-Holmes D, Barnes-Holmes Y, Power P, Hayden E, Milne R, Stewart I. Do you really know what you believe? Developing the Implicit Relational Assessment Pro-cedure (IRAP) as a direct measure of implicit beliefs. Ir Psychol 2006;32(7):169-77.

[44] Nosek BA, Smyth FL. A multitrait-multimethod validation of the Implicit Association Test: implicit and explicit attitudes are related but distinct constructs. Exp Psychol 2007:54(1):14 29.

[45] Dovidio JF, Kawakami K, Beach KR, Dovidio JF, Kawakami K, Beach KR. Implicit and explicit attitudes: examination of the relationship between measures of in-tergroup bias, implicit and explicit attitudes: examination of the relationship between measures of intergroup bias. In: Brown R, Gaertner SL, editors. Black-well handbook of social psychology: intergroup processes, [Internet]. Blackwell Publishers Ltd, Blackwell Publishers Ltd; 2008 [[cited 2012 Apr 15]. p. 175, 175-97, 197. Available from: http://onlinelibrary.wiley.com/doi/10.1002/ 9780470693421.ch9/summary].

[46] Nock MK, Park JM, Finn CT, Deliberto TL, Dour HJ, Banaji MR. Measuring the suicidal mind: implicit cognition predicts suicidal behavior. Psychol Sci 2010;21(4):511-7.

[47] Rooke SE, Hine DW, Thorsteinsson EB. Implicit cognition and substance use: a metaanalysis. Addict Behav 2008;33(10):1314-28.

[48] Dawson DL, Barnes-Holmes D, Gresswell DM, Hart AJ, Gore NJ. Assessing the implicit beliefs of sexual offenders using the implicit relational assessment procedure: a first study. Sex Abuse J Res Treat 2009;21(1):57-75.

[49] Testa SM, Brandt J. Do patients with psychogenic nonepileptic seizures have positive covert attitudes toward sickness? Epilepsy Behav 2010;19(3):323-7.

[50] Roberts NA, Burleson MH, Weber DJ, Larson A, Sergeant K, Devine MJ, et al. Emotion in psychogenic nonepileptic seizures: responses to affective pictures. Epilepsy Behav 2012;24(1):107-15

[51] Bakvis P, Roelofs K, Kuyk J, Edelbroek PM, Swinkels WAM, Spinhoven P. Trauma, stress, and preconscious threat processing in patients with psychogenic nonepileptic seizures. Epilepsia 2009;50(5):1001-11

[52] Golijani-Moghaddam N, Hart A, Dawson DL. The implicit relational assessment proce-dure: emerging reliability and validity data. J Context Behav Sci 2013;2(3-4):105-19.

[53] Barnes-Holmes D, Murtagh L, Barnes-Holmes Y, Stewart I. Using the implicit associ-ation test and the implicit relational assessment procedure to measure attitudes toward meat and vegetables in vegetarians and meat-eaters. Psychol Rec [Internet] 2011;60(2) [Available from: http://opensiuc.lib.siu.edu/tpr/vol60/iss2/6]

[54] McKenna I, Barnes-Holmes D, Barnes-Holmes Y, Stewart I. Testing the fake-ability of the Implicit Relational Assessment Procedure (IRAP): the first study. Int J Psychol Psychol Ther 2007;7(2):253-68

[55] Hussey I, Barnes-Holmes D. The implicit relational assessment procedure as a mea-sure of implicit depression and the role of psychological flexibility. Cogn Behav Pract [Internet] 2012;19(4):573-82 [[cited 2012 Aug 16]; Available from: http://www. sciencedirect.com/ science/article/pii/S1077722912000442]

[56] Binzer M, Stone J, Sharpe M. Recent onset pseudoseizures - clues to aetiology. Seizure J Br Epilepsy Assoc 2004;13(3):146-55.

[57] Spielberger CD. State-Trait Anxiety Inventory. The Corsini Encyclopedia of Psycholo-gy [Internet]. John Wiley \& Sons, Inc.; 2010 [[cited 2012 Jul 8]. Available from: http:// onlinelibrary.wiley.com/doi/10.1002/9780470479216.corpsy0943/abstract].

[58] Butcher JN, Spielberger CD. Advances in personality assessment. Lawrence Erlbaum Associates; 1995 [200 pp.]

[59] Kvaal K, Ulstein I, Nordhus IH, Engedal K. The Spielberger State-Trait Anxiety Inven-tory (STAI): the state scale in detecting mental disorders in geriatric patients. Int J Geriatr Psychiatry 2005;20(7):629-34.

[60] Kroenke K, Spitzer RL, Williams JBW. The PHQ-15: validity of a new measure for evaluating the severity of somatic symptoms. Psychosom Med 2002;64(2):258-66

[61] van Ravesteijn H, Wittkampf K, Lucassen P, van de Lisdonk E, van den Hoogen H, van Weert $\mathrm{H}$, et al. Detecting somatoform disorders in primary care with the PHQ-15. Ann Fam Med 2009;7(3):232-8

[62] Gámez W, Chmielewski M, Kotov R, Ruggero C, Watson D. Development of a measure of experiential avoidance: the Multidimensional Experiential Avoidance Questionnaire. Psychol Assess 2011;23(3):692-713.

[63] Barnes-Holmes D, Waldron D, Barnes-Holmes Y. Testing the validity of the implicit relational assessment procedure and the Implicit Association Test: measuring atti-tudes toward Dublin and country life in Ireland. Psychol Rec [Internet] 2010;59(3)[Available from: http://opensiuc.lib.siu.edu/tpr/vol59/iss3/5]

[64] Greenwald AG, Nosek BA, Banaji MR. Understanding and using the Implicit Associa-tion Test: I. An improved scoring algorithm. J Pers Soc Psychol 2003;85(2):197-216.

[65] Goldstein LH, Mellers JDC. Ictal symptoms of anxiety, avoidance behaviour, and dissociation in patients with dissociative seizures. J Neurol Neurosurg Psychiatry 2006;77(5):616-21

[66] Smith DF, Baker GA, Dewey M, Jacoby A, Chadwick DW. Seizure frequency, patientperceived seizure severity and the psychosocial consequences of intractable epilepsy. Epilepsy Res 1991;9(3):231-41.

[67] Thapar A, Kerr M, Harold G. Stress, anxiety, depression, and epilepsy: investigating the relationship between psychological factors and seizures. Epilepsy Behav 2009;14(1):134-40.

[68] Wilson TD, Lindsey S, Schooler TY. A model of dual attitudes. Psychol Rev 2000;107(1): 101-26.

[69] Myers L, Matzner B, Lancman M, Perrine K, Lancman M. Prevalence of alexithymia in patients with psychogenic non-epileptic seizures and epileptic seizures and predic-tors in psychogenic non-epileptic seizures. Epilepsy Behav 2013;26(2):153-7.

[70] Brown RJ, Bouska JF, Frow A, Kirkby A, Baker GA, Kemp S, et al. Emotional dysregulation, alexithymia, and attachment in psychogenic nonepileptic seizures. Epilepsy Behav 2013;29(1):178-83.

[71] Egloff B, Wilhelm FH, Neubauer DH, Mauss IB, Gross JJ. Implicit anxiety measure predicts cardiovascular reactivity to an evaluated speaking task. Emotion 2002;2(1):3-11. 
[72] Ponnusamy A, Marques JLB, Reuber M. Comparison of heart rate variability parame-ters during complex partial seizures and psychogenic nonepileptic seizures. Epilepsia 2012;53(8):1314-21.

[73] van Merode T, Twellaar M, Kotsopoulos IAW, Kessels AGH, Merckelbach H, de Krom MCTFM, et al. Psychological characteristics of patients with newly developed psychogenic seizures. J Neurol Neurosurg Psychiatry 2004;75(8):1175-7.

[74] Kalogjera-Sackellares D. Psychodynamics and psychotherapy of pseudoseizures. Norwalk, CT, US: Crown House Publishing Limited; 2004 [269 pp.].

[75] Linton SJ, Melin L, Götestam KG. Behavioral analysis of chronic pain and its manage-ment Prog Behav Modif 1984;18:1-42.

[76] Stone J, Carson AJ. The unbearable lightheadedness of seizing: wilful submission to dissociative (non-epileptic) seizures. J Neurol Neurosurg Psychiatry [Internet] 2013;84(7):822 [[cited 2013 Jul 21]; Available from: http://jnnp.bmj.com/content/ early/2013/03/27/jnnp-2012-304842].

[77] Frances PL, Baker GA, Appleton PL. Stress and avoidance in pseudoseizures: testing the assumptions. Epilepsy Res 1999;34(2-3):241-9.

[78] Festinger L. A theory of cognitive dissonance. Stanford University Press; 1957 [308 pp.].

[79] Rydell RJ, McConnell AR, Mackie DM. Consequences of discrepant explicit and im-plicit attitudes: cognitive dissonance and increased information processing. J Exp Soc Psychol 2008;44(6):1526-32.

[80] Linehan MM. Two-year randomized controlled trial and follow-up of dialectical behavior therapy vs therapy by experts for suicidal behaviors and borderline per-sonality disorder. Arch Gen Psychiatry 2006;63(7):757-66.
[82] Mayor R, Howlett S, Grünewald R, Reuber M. Long-term outcome of brief augmented psychodynamic interpersonal therapy for psychogenic nonepileptic seizures: seizure control and health care utilization. Epilepsia 2010;51(7):1169-76.

[83] Barry JJ, Wittenberg D, Bullock KD, Michaels JB, Classen CC, Fisher RS. Group therapy for patients with psychogenic nonepileptic seizures: a pilot study. Epilepsy Behav 2008;13(4):624-9.

[84] Goldstein LH, Chalder T, Chigwedere C, Khondoker MR, Moriarty J, Toone BK, et al. Cognitive-behavioral therapy for psychogenic nonepileptic seizures: a pilot RCT. Neurology 2010;74(24): 1986-94

[85] LaFrance Jr WC, Miller IW, Ryan CE, Blum AS, Solomon DA, Kelley JE, et al. Cognitive behavioral therapy for psychogenic nonepileptic seizures. Epilepsy Behav 2009;14(4): 591-6.

[86] LaFrance WC, Reuber M, Goldstein LH. Management of psychogenic nonepileptic seizures. Epilepsia 2013;54:53-67.

[87] Baslet G, Hill J. Case report: brief mindfulness-based psychotherapeutic intervention during inpatient hospitalization in a patient with conversion and dissociation. Clin Case Study 2011;10(2):95-109.

[88] Hunt M, Auriemma J, Cashaw ACA. Self-report bias and underreporting of depres-sion on the BDI-II. J Pers Assess 2003;80(1):26-30. 